\title{
How to Model Age-Related Motivational Reorientations in Risky Choice
}

\section{Commentary on Depping and Freund}

\author{
Rui Mata Ralph Hertwig \\ University of Basel, Basel, Switzerland
}

\author{
Key Words \\ Aging $\cdot$ Decision making $\cdot$ Motivation
}

Depping and Freund [this issue] provide food for thought by offering an account of how age-related motivational changes may translate into changes in decision processes. In a nutshell, their 'loss prevention' account goes like this: first, the aging decision maker faces a normal decline of resources, may they be cognitive (e.g., memory), social (e.g., death of loved ones), sensorimotor (e.g., hearing) or physical (e.g., health) in nature; second, experiencing this decline across domains, the decision maker's motivation (goal orientation or aspiration level) transforms from accruing gains to preventing or slowing-down losses; third, this reorientation amplifies his or her awareness of the potential of losses. In this commentary, we put Depping and Freund's proposal in context with other life span motivational theories and suggest ways to test the notion that the aging decision maker's motivational reorientation prompts changes in the valuation of gains and losses in decision making.

Choice under risk is one of the key topics of psychology and economics' research in decision making. It also offers a test bed for Depping and Freund's account because it allows researchers the detailed analyses of behavior in gain and loss domains as well as of possible asymmetries between the two. The valuation of gains and losses is the focus of Depping and Freund's as well as other motivational theories, for instance, Carstensen's [2006] socioemotional selectivity theory. Although some empirical work has already been conducted to understand the development of risky choice across the life span [see the review by Depping \& Freund, this issue; Mata, Josef, Samanez-Larkin, \& Hertwig, 2011], the still small number of studies and the heterogeneous findings do not afford us to arrive at clear-cut conclusions regarding the role of adaptive motivational reorientation on age differences in risky choice. In light of this still early state of the research field, we believe that both more concep-

\begin{tabular}{ll}
\hline KARGER & ( ) 2012 S. Karger AG, Basel \\
Fax +41 61 306 1234 & 0018-716X/11/0546-0368\$38.00/0 \\
$\begin{array}{l}\text { E-Mail karger@karger.ch } \\
\text { www.karger.com }\end{array}$ & $\begin{array}{l}\text { Accessible online at: } \\
\text { www.karger.com/hde }\end{array}$
\end{tabular}


tual as well as empirical work is needed. To this end, we take some steps towards mapping motivational accounts of the aging decision maker onto existing frameworks of decision making.

\section{Motivational Change in the Aging Decision Maker}

Depping and Freund argued convincingly that older adults' motivational goal structure could be affected by a need to maintain performance in a period of life in which losses, relative to gains, become the rule rather than the exception, thus making them reallocate their efforts into the prevention of losses and, concurrently, attenuate their striving for gains. This thesis follows naturally from previous work suggesting that older adults, in contrast to young adults, tend to focus on the prevention of losses rather than the striving for gains in several domains such as in the cognitive, physical, and social domains [Ebner, Freund, \& Baltes, 2006]. For example, older adults may be more likely to try to invest effort in maintaining their existing social contacts (avert losses) than in expanding their social network (strive for gains). Such a comprehensive motivation reorientation, as Depping and Freund argue, may have consequences for decision-making processes in general, and more specifically, for the valuation of losses and gains when making decisions.

Other theories have also linked up motivational changes associated with increased age to decision processes [e.g., Carstensen, 2006; Hanoch, Wood, \& Rice, 2007; Peters, Hess, Västfjäll, \& Auman, 2007]. These approaches tend to focus on changes related to the decision maker's motivation to regulate emotions with advanced age, in particular, the positivity effect, by which older adults tend to be motivated to use 'cognitive control mechanisms that enhance positive and diminish negative information' in an effort to enhance well-being [Mather \& Carstensen, 2005, p. 498]. Crucially, there are some findings that suggest that this process of adaptive accentuation of positive relative to negative information can evoke changes in decision processes [e.g., Löckenhoff \& Carstensen, 2007].

\section{The Prospect Theory Framework}

Depping and Freund employed concepts from a prominent theory of risky decision making, i.e. prospect theory [Kahneman \& Tversky, 1979], to explicate their account. According to the prospect theory, human choice can be modeled as follows: people behave as if they multiplied some function of probability ${ }^{1}$ and value, and then maximized. The value function [Tversky \& Kahneman, 1992] is:

$$
v(x)=\left\{\begin{array}{lll}
x^{\alpha} & \text { if } & x \geq 0 \\
-\lambda(-x)^{\beta} & \text { if } & x<0
\end{array} .\right.
$$

\footnotetext{
${ }^{1}$ Consequently, under the prospect theory framework, one could consider, in principle, both the value and probability weighting functions to account for age differences in choices involving gains, losses, or both. For instance, aging decision makers may weigh the impact of rare and common events differently than young adults [for such a proposal, see Peters et al., 2007]. Because motivational theories appear to focus on the valuation of gains and losses, we will focus here on the potential age differences in the value function.
}

How to Model Age-Related Motivational Reorientations in Risky Choice
Human Development 2011;54:368-375 
The existence of two different parameters shows that the theory makes a clear distinction between gains $(\alpha)$ and losses $(\beta)$, relative to a reference point. In the domain of gains, the prospect theory assumes that outcomes have decreasing marginal effects as more is gained (decreasing marginal sensitivity). This leveling off with increasing gains (when $0<\alpha<1$ ) leads to a concave value function indicative of riskaverse behavior (e.g., preferring a sure amount smaller than the expected value of a gamble over the opportunity to play the gamble). In the domain of losses, a similar leveling off of increases in disutility with increasing losses $(0<\beta<1)$ leads to a convex function, which is associated with risk-seeking behavior (e.g., preferring a gamble of possible losses over the sure loss smaller than the expected value of the gamble). Further, the prospect theory assumes an asymmetry in the steepness of the value functions for losses and gains, with a much steeper function for losses ('losses loom larger than gains'). In the aforementioned equation, this steepness in the loss function is reflected in a loss aversion parameter, $\lambda$, with $\lambda>1$.

Rather than just using concepts from the prospect theory, let us map Depping and Freund's 'loss prevention' and Carstensen's [2006] 'positivity' views onto the prospect theory framework. Such mapping, even if not fully justified, may help us elucidate in what respects the two motivational accounts differ. The 'loss prevention' view suggests at least two different ways in which motivational changes can prompt differences in decision making: first, older adults may show 'stronger sensitivity to losses and a weaker sensitivity to gains as compared to younger adults', and, second, there may be 'age-related changes in the asymmetry of gains and losses' [Depping \& Freund, this issue]. Figure 1 presents these two possible (and not mutually exclusive) scenarios under the prospect theory framework.

The first scenario (fig. 1a) suggests that there are age-specific differences in the decreasing marginal sensitivity to gains and losses. Specifically, when considering the domain of gains, older adults prove less sensitive to positive outcomes relative to young adults, that is, older adults derive less utility from any given gain compared to their younger counterparts. In the loss domain, in contrast, older adults are more sensitive to any given loss relative to young adults. According to the prospect theory, this pattern of gain/loss sensitivity has consequences for differences between young and older adults' risk taking, with older adults' reduced sensitivity in the gain domain giving rise to more risk-averse choice, and their increased sensitivity in the loss domain resulting in more risk-seeking choice relative to young adults. In terms of the value function, the $\alpha$ and $\beta$ parameters differ between younger and older decision makers but the loss aversion parameter $\lambda$ does not. In the second scenario (fig. $1 \mathrm{~b}$ ), in contrast, the change resides in the loss aversion parameter. That is, the asymmetry between losses and gains increases with age. Consequently, there are no 'older' and 'younger' value functions in the gain domain, and hence, no systematic age differences in risky choice in the gain domain. In the loss domain, however, the augmented loss aversion for older people implies age differences in risky choice.

The 'positivity' account 'postulates that age-related attempts to optimize emotional well-being generate increased positive emotional experiences and/or decreased negative emotional experiences over the life span' [Samanez-Larkin, Gibbs, Khanna, Nielsen, Carstensen, \& Knutson, 2007, p. 787]. Figure 1c depicts one possible operationalization of this account: in the domain of gains, older adults show increased sensitivity to gains such that they derive greater utility from a given gain, 


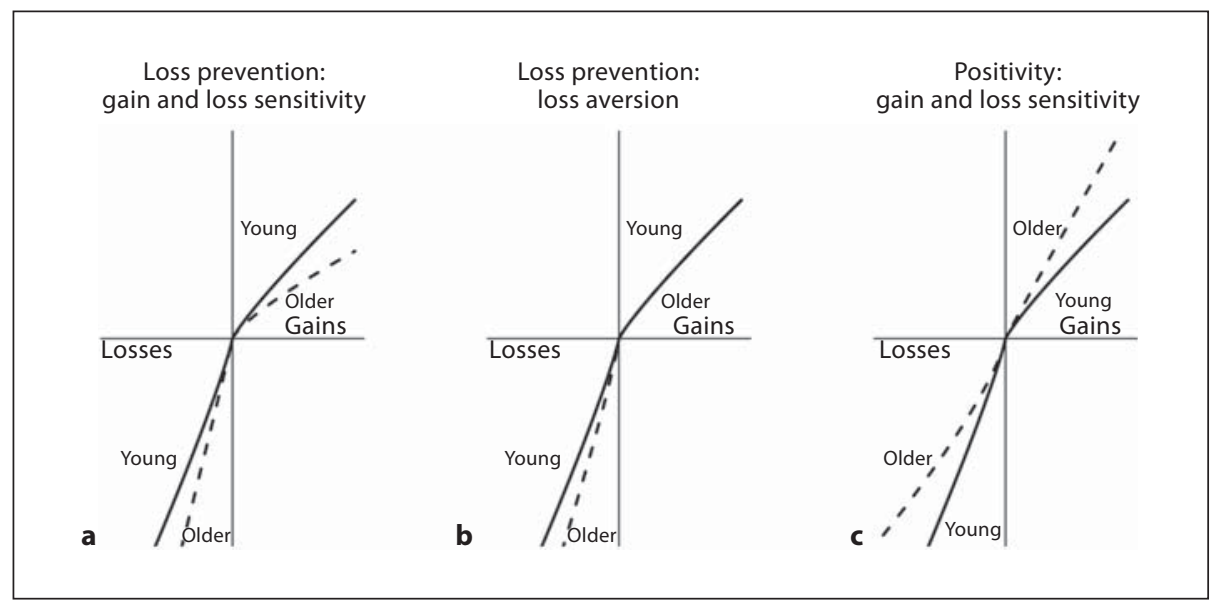

Fig. 1. Value functions for young adults (solid lines) and older adults (dashed lines) according to the 'loss prevention' and 'positivity' views of the role of motivation on age differences in decision making. The parameter values for younger adults are taken from Tversky and Kahneman [1992]: $\alpha=\beta=0.88, \lambda=2.25$. a The first 'loss prevention' scenario shows reduced sensitivity to gains and increased sensitivity to losses by older relative to young adults (older adults: $\alpha=0.78$, $\beta=0.98, \lambda=2.25$ ). $\mathbf{b}$ The second 'loss prevention' scenario shows similar sensitivity to gains and losses by younger and older adults but increased loss aversion by older relative to younger adults (older adults: $\alpha=\beta=0.88, \lambda=3$ ). c The 'positivity' scenario shows increased sensitivity to gains and reduced sensitivity to losses by older relative to young adults (older adults: $\alpha=0.98$, $\beta=0.78, \lambda=2.25$ ).

relative to young adults. In contrast, in the domain of losses, older adults' emotional regulation enables them to be less affected by a given negative loss, relative to young adults.

As can be seen in figure 1, translating Depping and Freund's loss prevention account and Carstensen's [2006] positivity account into the prospect theory's value function has an obvious advantage: it implies an immediate distinctive prediction. The loss prevention account predicts increased marginal sensitivity to losses and/or increased loss aversion with advanced age; the 'positivity' view predicts neither.

\section{Limitations of the Prospect Theory Framework}

One shortcoming of mapping the motivation accounts into the prospect theory is that it implies a focus on decision utility of the gains and losses associated with possible outcomes of the decision in question [Kahneman, 1999]. Decision utility reflects the attractiveness of an outcome in the context of a decision. Motivational accounts, however, are not necessarily limited to decision utility, or even primarily interested in decision utility. For example, motivational theories may be interested in distinguishing anticipated, experienced, and recalled attractiveness of both gain and loss outcomes [Mellers, 2000]. There is considerable debate con- 
cerning to what extent increased emotional regulation goals involve changes in processing positive information, negative information, or both [Hanoch et al., 2007; Peters et al., 2007], and some findings suggest that age differences may be found only during the anticipation of loss outcomes. Samanez-Larkin et al. [2007], for instance, found similar striatal and insular activations during gain anticipation of monetary rewards for younger and older adults, but a relative reduction in activation during loss anticipation for older relative to younger adults, and no age differences during the experience of gain or loss outcomes. In other words, age-specific changes may occur in the anticipation of losses but disappear during the experiencing of outcomes (and perhaps reappear in posterior recall) [Mather \& Carstensen, 2005]. To put it differently: only to the extent that experienced and recalled utility can be inferred from decision utility as conceptualized by the prospect theory (and that may be unwarranted) [Kahneman, 1999] do age-specific changes that unfold at the anticipation phase imply age differences during the experience and remembrance phases.

Another limitation of the prospect theory framework is that it is a successful theory of decision making only in the context of decisions from description, that is, in contexts in which outcomes and respective probabilities are known and conveniently summarized to decision makers [e.g., Erev et al., 2010]. Outside the laboratory, however, outcomes and probabilities are rarely known with certainty and served up to the decision maker on a platter. Consequently, people cannot help but to choose between options lacking a description of possible choice outcomes, let alone their probabilities. One method for overcoming such uncertainty is to sample the payoff distributions to learn about the options' attractiveness and, based on the experienced information, to come to a decision. Such decisions from experience [Hertwig, Barron, Weber, \& Erev, 2004] lead to choices that are systematically and predictably different from decisions from description [Hertwig \& Erev, 2009]. Several factors have been proposed to contribute to these differences, including the reliance on small samples, memory effects (e.g., recency), and distinct predecisional search policies in decisions from experience [e.g., Hau, Pleskac, Kiefer, \& Hertwig, 2008; Hertwig \& Pleskac, 2010; Hills \& Hertwig, 2010]. These factors - on all of them the prospect theory is mute - are particularly likely to be subject to age-specific changes.

Still another limitation of using the prospect theory framework as a theoretical sounding board of motivational theories is that the prospect theory assumes that choices can be described by stable preferences or attitudes in the valuation of gains and losses (and their probabilities). However, there is widespread skepticism in the decision making literature regarding the existence of stable risk preferences [Fox \& Tennanbaum, 2011; Hertwig \& Gigerenzer, 2011]. First, behavioral and self-report measures of risk taking show very limited predictive value of real-world risk taking [Dohmen, Falk, Huffman, Sunde, Schupp, \& Wagner, 2005]. Second, there is ample evidence that risky behavior varies as a function of activities [e.g., Hanoch, Johnson, \& Wilke, 2006; Weber, Blais, \& Betz, 2002], problem domain [Hsee \& Rottenstreich, 2004; Rottenstreich \& Hsee, 2001], and recent experience with particular outcomes or probabilities [Ungemach, Stewart, \& Reimers, 2011]. These and many related findings put the assumption of stable risk preferences (for both younger and older people) in jeopardy. 


\section{The Strategy Framework}

One alternative to the prospect theory framework that does not rest on the assumption of stable preferences involves specifying the heuristics or cognitive strategies that are used to search and integrate information prior to a decision [Brandstätter, Gigerenzer, \& Hertwig, 2006; Hertwig \& Gigerenzer, 2011]. Such models walk in the footsteps of Simon [1959] and represent possible implementation of his core concepts of aspiration levels and satisficing. In Simon's framework, motivational changes are conceptualized and modeled as changes in aspiration levels or thresholds that determine when enough information has been acquired or integrated. For example, a recent model that is explicit about the memory demands involved in choice embodies these ideas through a stopping rule that determines when search should be stopped in decisions from experience [Gonzalez \& Dutt, 2011]. More importantly, these strategies, in particular those that are lexicographic in nature (i.e., in which information is considered sequentially), offer a way to understand how it is possible that a user of the heuristic may seem to show risk-averse behavior one minute and risk-seeking behavior the next only to switch back to what appears to be risk aversion again. This pattern of behavior does not reflect unstable risk preferences, however, but rather follows directly from the sequential processing steps (each one representing a different risk preference) and the interaction of the heuristic's architecture with the choice environment [Hertwig \& Gigerenzer, 2011].

This strategy framework would suggest that age-specific differences in risk choice occur because (a) older people use different choice strategies than younger people (e.g., rely more often on the minimax heuristic, whereas younger people recruit the maximax heuristic), or (b) the strategy remains the same but some components of the strategy (e.g., the aspiration level used to determine whether two losses are treated to be identical in magnitude or different) [Brandstätter et al., 2006] change as a function of age.

\section{Where to Go from Here}

Let us briefly summarize what we see as immediate fruitful research directions that follow from Depping and Freund and our commentary. First and foremost, which of the implementations of the loss prevention and positivity accounts (fig. 1) predicts differences in risky choice (to the extent that they exist) between older and younger decision makers best?

Second, it has become clear that motivational theories need to specify the reach of their predictions, in particular, whether there are age-specific changes that unfold at the anticipation, experience, and remembrance phases. The temporal location of age-specific difference in the process of rendering a decision is an open question well deserving to be settled empirically.

Third, the distinction between decisions from experience and description seems particularly relevant to studying age differences in risky choice because of the differences in learning and memory demands that characterize the two paradigms, on the one hand, and age-related decline in learning, on the other [Eppinger, Hämmerer, \& $\mathrm{Li}, 2011$. On the basis of a meta-analysis, Mata et al. [2011] found that age-related differences in risky choice vary systematically as a function of the learning require-

How to Model Age-Related Motivational 
ments of the decision task. Older adults were more risk seeking compared to young adults when learning fostered risk-avoidant behavior, but were more risk averse when learning fostered risk-seeking behavior. In tasks involving decisions from description, however, young and older adults' choices did not show systematic differences for the majority of the tasks.

Fourth, the distinction between description-based and experience-based choices is also highly relevant for the 'loss prevention' and the 'positivity' accounts, and their focus on valuation of gains and losses. Mata et al. [2011] analyzed whether young and older adults differed in their decisions from description as a function of gain or loss framing. They found only a small number of studies that compared choices of young and older adults in the gain $(n=11)$ and loss domain $(n=10)$, respectively. All studies offered participants the choice between a risky gamble and a sure option (A: winning USD 10 with 0.5 probability, or USD 0 with 0.5 probability; B: winning USD 5 for sure). Across studies, the results suggest a heterogeneous pattern of findings but no mean difference in risk taking as a function of age for either gain or loss domains in decisions from description. In other words, decisions from descriptions do not appear to give rise to the implied differences in risky choices as a function of age (fig. 1). However, this lack of difference in description-based choices does not mean that no differences exist in experience-based choices. Unfortunately, Mata et al. [2011] were unable to conduct an analysis separately for gain and loss domains in decisions-from-experience studies. Some paradigms in decisions from experience are not amenable to such distinction or the data reported did not allow meaningful comparison for gain and loss domains separately.

\section{Conclusion}

Depping and Freund proposed that age-related changes in the motivation to improve versus maintain existing performance levels in important life domains implicate concurrent changes in the valuation of gains and losses in the process of making decisions. Research on human choice under risk is an adequate test bed for Depping and Freund's thesis. We suggest that taking steps toward translating the loss prevention notion (and competing theories) into the existing framework of risky choice can help to derive distinct predictions, thus increasing the power of future empirical tests.

\section{References}

Brandstätter, E., Gigerenzer, G., \& Hertwig, R. (2006). The priority heuristic: Making choices without trade-offs. Psychological Review, 113, 409-432.

Carstensen, L.L. (2006). The influence of a sense of time on human development. Science, 312, 19131915.

Dohmen, T., Falk, A., Huffman, D., Sunde, U., Schupp, J., \& Wagner, G.G. (2005). Individual risk attitudes: New evidence from a large, representative, experimentally-validated survey. IZA Discussion Paper, No. 1730.

Ebner, N.C., Freund, A.M., \& Baltes, P.B. (2006). Developmental changes in personal goal orientation from young to late adulthood: From striving for gains to maintenance and prevention of losses. Psychology and Aging, 21, 664-678. 
Eppinger, B., Hämmerer, D, \& Li, S.C. (2011). Neuromodulation of reward-based learning and decision making in human aging. Annals of the New York Academy of Sciences, 1235, 1-17.

Erev, I., Ert, E., Roth, A.E., Haruvy, E., Herzog, S., Hau, R., Hertwig, R., Stewart, T., West, R., \& Lebiere, C. (2010). A choice prediction competition: Choices from experience and from description. Journal of Behavioral Decision Making, 23, 15-47.

Fox, C.R., \& Tannenbaum, D. (2011). The elusive search for stable risk preferences. Frontiers in Psychology, 2, 298.

Gonzalez, C., \& Dutt, V. (2011). Instance-based learning: Integrating sampling and repeated decisions from experience. Psychological Review, 118, 523-551.

Hanoch, Y., Johnson, J.G., \& Wilke, A. (2006). Domain specificity in experimental measures and participant recruitment. Psychological Science, 17, 300-304.

Hanoch, Y., Wood, S., \& Rice, T. (2007). Bounded rationality, emotions and older adult decision making: Not so fast and yet so frugal. Human Development, 50, 333-358.

-Hau, R., Pleskac, T.J., Kiefer, J., \& Hertwig, R. (2008). The description-experience gap in risky choice: The role of sample size and experienced probabilities. Journal of Behavioral Decision Making, 21, 493-518.

Hertwig, R., Barron, G., Weber, E.U., \& Erev, I. (2004). Decisions from experience and the effect of rare events in risk choice. Psychological Science, 15, 534-539.

Hertwig, R., \& Erev, I. (2009). The description-experience gap in risky choice. Trends in Cognitive Sciences, 13, 517-523.

-Hertwig, R., \& Gigerenzer, G. (2011). Behavioral inconsistencies do not imply inconsistent strategies. Frontiers in Psychology, 2, 292.

Hertwig, R., \& Pleskac, T.J. (2010). Decisions from experience: Why small samples? Cognition, 115, 225-237.

Hills, T.T., \& Hertwig, R. (2010). Information search in decisions from experience: Do our patterns of sampling foreshadow our decisions? Psychological Science, 21, 1787-1792.

Hsee, C.K., \& Rottenstreich Y. (2004). Music, pandas and muggers: On the affective psychology of value. Journal of Experimental Psychology: General, 133, 23-30.

Kahneman, D. (1999). Objective happiness. In D. Kahneman, E. Diener, \& N. Schwarz (Eds.), Well-being: The foundations of hedonic psychology (pp. 3-25). New York: Russell Sage.

Kahneman, D., \& Tversky, A. (1979). Prospect theory: An analysis of decision under risk. Econometrica, 47, 263-291.

Löckenhoff, C.E., \& Carstensen, L.L. (2007). Aging, emotion, and health-related decision strategies: Motivational manipulations can reduce age differences. Psychology and Aging, 22, 134-146.

Mata, R., Josef, A.K., Samanez-Larkin, G.R., Hertwig, R. (2011). Age differences in risky choice: A meta-analysis. Annals of the New York Academy of Sciences, 1235, 18-29.

Mather, M., \& Carstensen, L.L. (2005). Aging and motivated cognition: The positivity effect in attention and memory. Trends in Cognitive Sciences, 9, 496-502.

Mellers, B.A. (2000). Choice and the relative pleasure of consequences. Psychological Bulletin, 126, 910924.

Nilsson, H., Rieskamp, J., \& Wagenmakers, E.J. (2011). Hierarchical Bayesian parameter estimation for cumulative prospect theory. Journal of Mathematical Psychology, 55, 84-93.

Peters, E., Hess, T.M., Västfjäll, D., \& Auman, C. (2007). Adult age differences in dual information processes: Implications for the role of affective and deliberative processes in older adults' decision making. Perspectives on Psychological Science, 2, 1-23.

Rottenstreich, Y., \& Hsee, C.K. (2001). Money, kisses, and electric shocks: An affective psychology of risk. Psychological Science, 12, 185-190.

Samanez-Larkin, G.R., Gibbs, S.E.B., Khanna, K., Nielsen, L., Carstensen, L.L., \& Knutson, B. (2007). Anticipation of monetary gain but not loss in healthy older adults. Nature Neuroscience, 10, 787791.

Simon, H.A. (1959). Theories of decision-making in economics and behavioral science. American Economics Review, 49, 253-283.

Tversky, A., \& Kahneman, D. (1992). Advances in prospect theory: Cumulative representation of uncertainty. Journal of Risk and Uncertainty, 5, 297-323.

Ungemach, C., Stewart, N., \& Reimers, S. (2011). How incidental values from our environment affect decisions about money, risk, and delay. Psychological Science, 22, 253-260.

Weber, E.U., Blais, A.R., \& Betz, N.E. (2002). A domain-specific risk-attitude scale: Measuring risk perceptions and risk behaviors. Journal of Behavioral Decision Making, 15, 263-290.

How to Model Age-Related Motivational Reorientations in Risky Choice
Human Development 2011;54:368-375 